\title{
Sobre a performance de sofrimento na web: narrativas de mães de crianças com condiçôes crônicas complexas de saúde em uma revista eletrônica
}

\section{I ${ }^{1}$ Anita Silva Paez, 2 Martha Cristina Nunes Moreira I}

Resumo: O objetivo deste artigo é discutir a performance de sofrimento a partir das narrativas de mães de crianças com condiçóes crônicas complexas de saúde veiculadas em uma revista eletrônica, seguindo também a pista de alguns links que levam a blogs. A visibilidade dos conteúdos compartilhados na internet, seja qual for a plataforma, e sua crescente função social de construção conjunta levam-nos a voltar nossa atençáo especificamente para este espaço contemporâneo. A partir de uma imersão de inspiração etnográfica nos escritos, foram identificados movimentos engendrados pelas narrativas: captura, afirmação de um lugar, constituição de um vetor de forças e luta simbólica. $\mathrm{Na}$ forma de um ensaio, buscou-se articular discursivamente o material empírico com questôes teóricas. A internet é um importante recurso de aproximação e vinculação ao ensejar a circulação de narrativas contrahegemônicas. Mostrar o rosto e o nome, próprios e do filho, pode fazer parte de um movimento que afirme uma individualidade sofredora, mas pode também culminar na produção de novos sentidos, ampliando o campo de possibilidades, inclusive simbólicas, para mães e crianças.

> Palavras-chave: doença crônica; criança; narrativas.

\author{
1 Instituto Fernandes Figueira, \\ Fundação Oswaldo Cruz. Rio de \\ Janeiro-RJ, Brasil (anita.paez@iff \\ fiocruz.br) \\ ORCID: 0000-0002-0740-2972. \\ ${ }^{2}$ Instituto Fernandes Figueira, \\ Fundação Oswaldo Cruz. \\ Rio de Janeiro-RJ, Brasil \\ (marthacnmoreira@gmail.com) \\ ORCID: 0000-0002-7199-3797.
}

Recebido em: 16/10/2018 Aprovado em: 19/11/2018 Revisado em: 15/01/2019 


\section{Introdução}

A existência de crianças com condições crônicas complexas de saúde, tornada possível pelo desenvolvimento da biotecnologia e seus aparatos, impóe-nos o desafio de produzir conhecimentos que instrumentalizem nossas práticas como profissionais de saúde e ampliem o horizonte crítico na concepção de novos caminhos e possibilidades simbólicas. É fundamental que possamos reconhecer estas crianças e seus familiares como protagonistas de suas histórias e destas novas construçôes, dando relevo à dimensáo da experiência.

O presente artigo destaca o protagonismo de mulheres que compartilham suas experiências em uma revista eletrônica norte-americana, Complex Child, escrita pelos pais e para os pais de crianças ditas complexas. Compartilhando seus artigos em língua inglesa, a revista agrega colaboradores residentes nos Estados Unidos, Austrália, Reino Unido e em outros países da Europa.

Nosso olhar busca ultrapassar uma aparente distância cultural. Pressupomos que, transcendendo fronteiras locais, a revista é capaz de amplificar perspectivas comuns sobre a experiência de cuidar de um(a) filho(a) com um corpo alterado por malformaçóes e por tecnologias invasivas, mobilizadoras de outras formas de existência humana. A utilização de um recorte estrangeiro não significa perdermos o contexto nacional no qual estamos inseridos. A realidade brasileira, ainda que muito marcada pelas iniquidades no acesso à saúde, se aproxima da internacional se considerarmos as dependências tecnológicas e a demanda intensiva e rotineira de cuidados complexos, na qual o recurso do home care, ou cuidado domicilar, é cada vez mais acionado com importantes repercussōes (MOREIRA et al., 2017).

O impacto da vida mediada pelo adoecimento crônico desde o nascimento e na infância vem sendo objeto de estudos que dão relevo à necessidade de reorganização familiar e ao estresse a que os cuidadores estão expostos (ALVES; BUENO, 2018; SMITH; CHEATER; BEKKER, 2013; LEITE et al., 2012; SWALLOW et al., 2011; SILVA et al., 2010; MARCON et al., 2007). No entanto, esse processo de viver e cuidar de uma criança complexa pode se revelar também um território para criaçôes e estabelecimento de redes de relaçôes (MOREIRA et al., 2018; PAEZ; MOREIRA, 2016), e não somente um viver capturado pela doença e por suas limitaçôes. Dessa forma, torna-se importante discutir felicidade e, portanto, infelicidade, em um contexto simbólico em que a doença e a limitação física são 
hegemonicamente associadas ao sofrimento, a fim de abrir outras possibilidades para o encontro e o cuidado a essas famílias e crianças.

Ao assumirmos que a doença não captura todos os processos do viver, visamos enfrentar o imaginário prevalente sem ignorar os muitos desafios impostos e sem celebrar uma felicidade compulsória (BIRMAN, 2010; FREIRE FILHO, 2010).

Os artigos que compóem a revista Complex Child, apesar da diversidade de elementos e recursos mobilizados, apresentam possibilidades de subjetivação da experiência de parentalidade no contexto das condiçóes crônicas complexas para além da assunção do lugar de vítima ou do lugar de "mãe especial”, destinada a dar conta com eficiência de todas as demandas do filho. Optamos por iluminar em nossa discussão a figura da mãe, pois, apesar de não ser este o enfoque da revista, mais de $90 \%$ dos artigos foram escritos por mulheres. A visibilidade dos conteúdos compartilhados na internet, seja qual for a plataforma, e sua crescente função social de construção conjunta leva-nos a voltar nossa atenção especificamente para este espaço contemporâneo.

Objetivamos desenvolver uma discussão em torno da performance de sofrimento na internet a partir das narrativas veiculadas na revista, seguindo também a pista de alguns links que levam a blogs, e, na forma de um ensaio teórico, articular discursivamente o material empírico com questôes teóricas.

\section{Caminho metodológico}

A revista eletrônica Complex Child, ${ }^{1}$ lançada em 2008, de acesso aberto, mensal e gratuito, foi idealizada por uma professora universitária estadunidense, mãe de uma menina com múltiplas deficiências. O objetivo manifesto no número de estreia era compartilhar, em linguagem simples, conhecimentos práticos adquiridos a partir do cuidado de uma "criança complexa". O termo em nenhum momento é definido, pois, segundo a editora, a revista propóe-se como recurso a todos que puderem se beneficiar de seus artigos. Sua página principal é convidativa, colorida e ilustrada com fotos de crianças com deficiências visíveis e/ou em uso de aparelhos diversos para mobilidade ou mesmo funçôes críticas como respiração. $\mathrm{O}$ acesso aos artigos é simples e a busca por conteúdos específicos é facilitada por menus na parte superior da tela. Todos os artigos estão em inglês, o que facilita sua circulação.

Após cada artigo, a maioria das autoras disponibiliza uma breve apresentação pessoal, sem seguir qualquer padráo e sem referências a dados como raça/cor ou situação socioeconômica. 
As edições de Complex Child trazem um tema principal, como por exemplo, acessibilidade, estresse do cuidador e o brincar. Os artigos conjugam o compromisso com o caráter informativo - em especial aqueles assinados pela editora - sem perder sua potência envolvente e narrativa. Predomina o conteúdo da experiência, a reflexão sobre as memórias e a construção de uma história pessoal que se quer compartilhar.

Sendo uma revista on-line, links ou atalhos levam o leitor a explorar outros recursos ou conteúdos como, no caso da revista em questão, arquivos de áudio e vídeo e, principalmente, páginas de organizações e blogs pessoais, espécies de diários on-line. Outro atributo fundamental do campo digital é a possibilidade de interação, e a revista reserva um campo de comentários após cada um dos artigos. Esse desenho e linguagem web fazem com que o narrador nos ofereça caminhos, e assim o leitor literalmente é conduzido pela experiência narrativa, com liberdade para ir, vir, parar, seguir a seu gosto e vontade, manejando seus limites. Apesar de não terem sido explorados em sua totalidade, alguns links e comentários pertinentes para nossa análise foram incluídos como fontes.

Como não havia entrevistado as mulheres ou transcrito suas falas ${ }^{2}-$ mas acessado suas narrativas públicas na revista -, o projeto inicial de trabalharmos com análise temática revelou-se pouco produtivo. Igualmente, a tarefa de traduzir os originais em inglês para o português, a partir de um desejo de gerar fidedignidade, revelou-se infrutífera. Foi lidando com a frustração das traduçôes imperfeitas - e dos modelos de análise que pareciam não valorizar as narrativas - que pude experienciar um momento de "revelação": ao emprestar as minhas palavras para essas histórias táo densas, eu as estava tornando um pouco minhas. $\mathrm{O}$ encontro verdadeiro com meu campo de pesquisa se deu quando deixei de lado também a preocupação com a contabilização da recorrência de temas e me permiti ser afetada. A dimensão da afetação na pesquisa é abordada por FavretSaada (2005), que resgata o lugar de uma "sensibilidade" que náo se confunde com empatia. Na empatia, para a autora, o lugar do outro é tomado por meio de nossa suposta capacidade de penetrá-lo, mantendo uma dominação do pesquisador sobre as experiências "exóticas". Na afetação, o que está em jogo é ser tomado pelo desconhecido, ser dominado e experimentar a revisão da própria posição. A partir de uma "crise", somos enfeitiçados, como Saada, por aqueles que desejaríamos "observar". A partir deste reposicionamento, os temas puderam emergir da leitura 
cuidadosa e a análise se deteve na performance do sofrimento abordada através dos movimentos engendrados pela narrativa.

Interpretamos o material que compóe a revista como uma narrativa etnográfica, que remete à experiência de famílias que cuidam de suas crianças em situação de cronicidade e complexidade. Neste contexto, tornar pública a experiência vivida tornase um meio de se (re)construir e criar redes. Mergulhar nas narrativas desta revista tornou-se um momento de inspiração etnográfica. Por método etnográfico entendese a atividade de pesquisa no campo, por períodos relativamente prolongados, com contato direto com o objeto de estudo, seguido pela sistematização da experiência (LABURTHE-TOLRA; WARNIER, 1997). Nesse espaço de comunicação pública da experiência, mesmo não realizando observações off-line e nem mesmo uma abordagem direta aos sujeitos, consideramos que o observador/pesquisador transforma-se pela afetação provocada pelo encontro com as narrativas.

Miller e Slater (2004) instrumentalizam nossa reflexão sobre as possibilidades de um trabalho etnográfico conduzido em ambiente $100 \%$ on-line. Com os autores, estamos considerando que, para um trabalho ser considerado etnográfico, não está em questão se foram pesquisados contextos off-line, mas se se partiu do compromisso maior de relacionar o fenômeno a contextos mais amplos. É possível, e de fato necessário, contextualizar o que é observado em termos de aspectos como, no nosso caso, a exclusão simbólica de mulheres cujas experiências de maternidade se distanciam em muito da norma e os projetos de felicidade que precisam ser inventados.

O campo de pesquisa torna-se, portanto, não um lugar geográfico ou "a internet", mas o processo, o projeto destas mulheres em relação aos seus filhos. Por uma escolha metodológica e ética, conduzimos uma "observação silenciosa" ou lurking (FRAGOSO; RECUERO; AMARAL, 2011). Entretanto, cabe considerar que a não influência do pesquisador na produção do conteúdo a ser analisado não exclui a subjetividade do mesmo. A posição de quem observa estará necessariamente em questão no trabalho etnográfico.

Apostamos em um trabalho que, se afastando de uma forma tradicional de reflexão e análise, articula-se como escrita dinâmica na qual ganharão destaque os seguintes eixos, identificados como movimentos narrativos: captura - o leitor na cena, afirmação de um lugar, constituição de um vetor de forças - emoçóes em diálogo e luta simbólica. 


\section{Primeiro movimento: captura - o leitor na cena}

Em um dos artigos, escrito por uma mãe, são apresentadas minúcias da cena da morte de uma criança. O pai a encontra pela manhã de bruços na cama, morta. Os outros dois filhos vão para trás do sofá, aterrorizados. A mãe está a quatro horas de distância, e desaba no cháo do banheiro da pousada ao receber a notícia (SCHAEFFER, 2017). Por que ela conta esses detalhes? Por que eu os repito aqui?

A descrição crua de uma cena de intenso sofrimento repercute para além do nível da compreensão de quem lê, mobilizando respostas subjetivas e mesmo corporais. Através da escolha das palavras, é literalmente montada uma cena, para onde o leitor é arrastado. Este seria o primeiro movimento engendrado pelas narrativas. A partir de uma relação inicial de exterioridade, ocorre a captura de quem lê. Quais as consequências para a interação e a construção de vínculos desta demonstração pública de sofrimento nas plataformas digitais? O conceito de performance pode nos ajudar a compreender o que está em questão quando pessoas precisam (ou escolhem) se mostrar publicamente de uma maneira ou de outra.

Para Schechner (2006), performar é mostrar-se fazendo: apontar, sublinhar e demonstrar a ação. Para o autor, fazer e mostrar estão sempre num continuum. Uma performance, portanto, ocorre apenas em ação, interação e relação. A performance não está em nada, mas entre. Quando um indivíduo se apresenta perante outros, ele tem muitos motivos para tentar controlar a impressão que causa. A performance, para Goffman (2002), pode ser definida como toda atividade de um dado participante da interação que sirva para influenciar de algum modo qualquer outro participante.

A narrativa como performance é um aporte teórico-metodológico que sustenta um diálogo importante com o interacionismo simbólico, assumindo a importância do contexto, microrrelaçóes e agência. A narrativa, nesta forma de entendimento, surge como lugar situado para conhecermos a vida social e os “(...) efeitos discursivos que o ato de contar uma história provoca notadamente na construção de identidades sociais, subjetividades ou sociabilidades". (MOITA LOPES, 2010). Neste sentido, a narrativa alcança status de prática discursivo-social e, portanto, performance.

Goffman e outros autores interacionistas formulam suas ideias sempre a partir do encontro humano face a face. A interação mediada pela tecnologia possibilita trocas entre pessoas que se encontram distantes no espaço e tempo. Recursos como 
a publicação de fotos e narrativas de detalhes cotidianos, vinculados ao diálogo via comentários, por exemplo, criam a sensação de "face a face". É bastante comum, nas mais diversas plataformas digitais, que pessoas testemunhem um sentimento de proximidade e vinculação a outras que nunca encontraram pessoalmente, e talvez nunca venham a encontrar.

Através de suas narrativas, as autoras procuram sair do plano da experiência solitária e levar o outro a experimentar algo de seu sofrimento. Eu sonhei com a cena do falecimento.

\section{Segundo movimento: afirmação de um lugar}

Segundo Freire Filho (2010), desde as últimas décadas do século XX, a expansão da capacidade e das possibilidades de ser feliz sobressai como um poderoso fio condutor de nossas vidas. Trata-se de uma ideia fixa tão dominadora que o autor alerta para o risco de sua especificidade histórica passar despercebida. Neste contexto ocidental de exacerbação dos projetos individualizantes e neoliberais, a felicidade vem sendo tratada como bem de consumo (FREIRE FILHO, 2010). Lasch (1983), analisando a sociedade americana, aponta conexôes entre o narcisismo e certos padróes característicos da cultura contemporânea. Viver para o momento é a paixão predominante - viver para si, não para os outros que virão a seguir, ou para a posteridade. Estaríamos rapidamente perdendo o sentido de continuidade histórica, o senso de pertencermos a uma sucessão de gerações que se originaram no passado e que se prolongarão no futuro (LASCH, 1983).

Neste contexto, a felicidade se insinua, no imaginário popular e científico, como um projeto de engenharia individual (FREIRE FILHO, 2010). A visão meritocrática da felicidade a transforma em algo a ser atingido por um processo de autodesenvolvimento e expansão pessoal. Lendo Lasch (1983), podemos dizer que, hoje em dia, as pessoas desejam não a salvação, mas o sentimento, a ilusão momentânea de bem-estar pessoal, saúde e segurança psíquica. E, além de estar bem, torna-se importante aparentar saúde, prosperidade material e felicidade. As plataformas digitais prestam-se bem a este tipo de "exibição".

O lado perverso desta injunção cultural é a exclusão de pessoas que vivem situaçôes que, a princípio, não parecem abarcáveis por esta construção. 
Mesmo para as mães de crianças com condiçôes complexas de saúde, notadamente para as que têm acesso a maiores recursos financeiros e de informação, há a alternativa de se engajarem numa luta para acompanhar a felicidade compulsória reinante nas redes mostrando-se belas e produtivas, cercando os filhos "diferentes" com tudo que a tecnologia pode proporcionar, além de cuidadores pagos e terapias diversas. Entretanto, para a maioria das mulheres resta uma abdicação raivosa ou resignada deste ideal. Para elas, prevalece o velho modelo cultural que cola a maternidade ao padecimento.

O sofrimento, na cultura judaico-cristá, é fortemente associado ao feminino e em especial à maternidade. Desde a bíblica expulsão do Éden, as descendentes de Eva devem parir com dor e seguir "padecendo no paraíso" o exemplo de Maria. A mãe que se sacrifica pelo filho, tema disseminado como valor social, liga, portanto, a figura feminina ao padecimento e à abnegação, formas de sublimar o pecado original de ser mulher. Se este modelo se coloca para todas as mulheres, é ainda maior a carga de sofrimento destinada às mães de crianças doentes.

Pelos motivos acima expostos, não foi surpreendente quando, em trabalho anterior, com mães de crianças com síndrome do intestino curto (condição crônica complexa e de grande gravidade), identificamos um núcleo de significação da maternidade ligado à ideia do cuidado como algo árduo e do sofrimento como presença constante (PAEZ; MOREIRA, 2016). Muitas mulheres parecem afirmar-se nesse lugar e nele buscar seu valor como mães.

Há dois anos e meio eu deixei a profissão para a qual passei anos estudando e treinando, e também a carreira que construí nas últimas duas décadas. [...] Eu troquei as salas do tribunal para ser, além de uma máe que fica em casa, a principal cuidadora de minha filha. (NUPPONEN, 2017).

Este seria mais um significado da "exibição" de sofrimento, que relacionamos com um segundo movimento narrativo, de afirmação e construção de legitimidade: a delimitação de um campo de desvelo e cuidado feminino. Os relatos de noites sem dormir, exaustâo física e mental das mulheres e abdicação de uma vida profissional e social em nome dos cuidados ao filho são recorrentes e podem ser vistos como uma exacerbação das tarefas maternas comuns, relacionadas à criação de filhos típicos. Entretanto, chama-nos a atenção a ausência de reflexão sobre gênero nos artigos da revista. 


\section{Terceiro movimento: constituição de um vetor de forças - emoçôes em diálogo}

As narrativas, ao engendrar movimentos de aproximação, captura e afirmação pública, estabelecem um circuito ou vetor de forças. As emoçôes se colocam em diálogo com o espaço público.

A ideia de que as emoçôes são indescritíveis, subjetivas e privadas é um obstáculo ao progresso de nossa compreensão ética e científica (SOLOMON, 2015). Rezende e Coelho (2010) afirmam que fazer uma "antropologia das emoçôes" é colocar em xeque essas convicções, tendo como base a verificação de que os sentimentos são tributários das relações sociais e do contexto cultural em que emergem. Sua eclosão seria pautada por "regras de relacionamento", que os tornam legítimos e esperados em relaçóes governadas por expectativas. Isto não significa negar que as emoções sejam psicológicas, mas afirmar que o psicológico não se equipara com o que está "na" psique, e sim com um conjunto distinto de processos direcionados para o mundo e no mundo (SOLOMON, 2015).

Para Rezende e Coelho (2010), os conceitos de emoção devem ser vistos como elementos de práticas ideológicas locais: as emoçôes passam a ser tomadas como um idioma que define e negocia as relaçôes sociais entre uma pessoa e as outras. Cada cultura tem suas "regras de exibição". Cada indivíduo, com base na sua experiência e posição social, aprende como deve expressar suas emoções e que emoçôes devem ser expressas (REZENDE; COELHO, 2010).

As regras de exibição são colocadas em disputa quando um grupo de pessoas, no caso as mães de crianças complexas, oferece ao olhar público narrativas e imagens de "corpos anormais", um mundo que foi mantido desde sempre na penumbra dos quartos fechados e instituiçóes asilares.

Estamos acostumados a pensar nas emoçôes como experiências na primeira pessoa. No entanto, na medida em que possamos entendê-las como estratégias, vemos que a perspectiva em que melhor aprendemos sobre as emoções é na segunda pessoa, na interação e troca interpessoais (SOLOMON, 2015). Seguindo este mesmo entendimento, Candace Clark aborda a compaixão como uma "emoção social", que envolve e conecta dois ou mais atores sociais. Não existe um "sentimento puro", mas emoçôes vinculadas a ordens negociadas (REZENDE; COELHO, 2010). 
É importante que nos distanciemos da ideia de ser "natural" que pais de crianças doentes se sintam infelizes.

Caro doutor, você me disse que meu bebê de cinco meses havia nascido com uma doença fatal (...) Você disse que ele se tornaria "vegetativo" e morreria antes de seu segundo aniversário. Você me recomendou não me apegar a ele e, em vez disso, encontrar uma boa instituição que pudesse recebê-lo. (...) Eu te odiei naquele dia. Você, de maneira casual e fria, tentou acabar com toda esperança de amor, felicidade e futuro. Eu não te odeio mais, tenho pena de você. (RANDELL, 2018).

A cada dia, mães e pais têm seus filhos diagnosticados com doenças e condiçóes graves, desconhecidas para eles, dramáticas. Ainda escutam para "não se apegar demais", ainda sentem o peso dos olhares que julgam e apequenam suas escolhas.

Outra mãe relata na revista a discussão com um homem sobre o uso da vaga de estacionamento para deficiente. Este se mostrou indignado quando ela reivindicou o uso da vaga, e lhe disse que pessoas como ela colocam seres incapazes no mundo e ainda exigem privilégios. Apesar das agruras que a realidade impóe, a escolha destas mulheres e de muitas outras tem sido colocar às claras, denunciar, gritar, seguir mostrando seu filho tanto on-line como em pessoa, nos lugares públicos.

$\mathrm{O}$ que pensar de uma exibição do sofrimento de ser mãe de uma criança que carrega em si os signos da anormalidade? Rompe-se uma barreira de silêncio em relação ao tema abordado. Falar abertamente sobre corpos doentes, malformados, inclusive mostrando-os em fotos, significaria em outros momentos históricos uma incivilidade imperdoável.

Uma possibilidade de entendimento desta performance de sofrimento na web seria tomá-la como forma de angariar compaixão. Para além de benefícios mais concretos, a compaixão traz compensaçôes por si mesma como, para Clark (2007), um sentido de intersubjetividade, conexão e compreensão. Como outras emoções, a compaixão segue regras culturais implícitas, nem sempre conscientes. Caso "erre a mão" na manifestação de sofrimento, o sujeito pode ser criticado, em lugar de receber apoio. Por exemplo, a mãe de um menino com múltiplas deficiências, que mantém um blog pessoal com muitos acessos e também escreve para a revista eletrônica Complex Child, relatou um movimento no qual algumas mães compartilharam fotos de seus filhos deficientes deitados no chão de banheiros públicos (GEORGE, 2016a). O objetivo era atrair visibilidade para a necessidade de banheiros adaptados para pessoas com deficiências severas (que, muitas vezes, precisam realmente ser 
trocadas no chão); entretanto, as imagens geraram grande desconforto na rede e suscitaram críticas contundentes. Como forma talvez de "contornar" a sensibilidade dos que se sentiram ofendidos, esta mãe específica divulgou uma montagem na qual o rosto de seu filho aparecia num boneco de papel, este deitado no chão de um banheiro público.

Clark (2007) delineia uma "economia da compaixão", na qual ela pode ser inclusive drenada. Em geral, as pessoas estariam dispostas a manifestar solidariedade e oferecer apoio por um período finito de tempo. Caso o sofrimento de alguém persista, é provável que se "gaste" a compaixão dos outros até o fim.

No primeiro mês após sua morte, as pessoas estavam presentes, escutavam, queriam saber os detalhes. [...] Mas agora, o que eu encontro nas pessoas é uma estranheza. (SCHAEFFER, 2014).

A formação de outras redes, em muito facilitada pela conectividade digital, seria uma maneira de receber apoio de novas fontes. Uma mulher utilizou-se de um recurso narrativo bastante interessante em uma das postagens de seu blog. Em lugar de dizer que seu filho é totalmente dependente para as atividades da vida diária, o que seria suficiente para a compreensão de quem lê, fez uma descrição minuciosa e repetitiva de todos os cuidados que precisa dispensar ao menino ao longo do dia (GEORGE, 2016b). O texto recebeu muitos comentários de solidariedade. Destacamos aqui a dimensão negociada da compaixão.

As condiçôes crônicas complexas de saúde na infância, por sua novidade, ainda não têm lugar no imaginário social. As mães se veem na necessidade de reivindicar simbolicamente o reconhecimento de seu sofrimento como algo de igual (ou maior) magnitude que, por exemplo, a condição de ser mãe de uma criança com câncer.

[...] Nossa sociedade, como um todo, é mais solidária em relação às chamadas 'crianças normais' que inesperadamente desenvolvem uma doença do que àquelas com condiçóes crônicas e complexas que as acompanham pela vida. Quando uma condição de curso mais agudo, como o câncer, é diagnosticada, a criança será tratada e curada ou morrerá. Em qualquer dos casos, a jornada nấo será assim tão longa [...]. Uma vida inteira vivida nas nuances de cinza de uma doença crônica é um desafio muito maior do que a maioria das pessoas pode começar a compreender. (AGRAWAL, 2016, s.p.)

\section{Quarto movimento: luta simbólica}

Num quarto movimento narrativo, o jogo simbólico de expressão e compartilhamento do sofrimento gera aprendizado e deslocamentos. 
Veena Das (2008) defende que o conhecimento antropológico em relação ao sofrimento esteja atento à violência onde quer que ocorra no tecido da vida, abrindose à dor do outro. Abordando tragédias coletivas, a autora se pergunta acerca das tarefas da sobrevivência em que a (re)construção do eu permite habitar novamente o espaço do cotidiano. No Brasil, Vianna e Farias (2011) abordam o sofrimento e luta por justiça de mães de vítimas da violência policial. Apesar da especificidade da vitimização pela violência do Estado, há aproximações possíveis deste trabalho com a questão das mães de crianças com condiçôes crônicas complexas. As autoras nos falam do acionamento da condição de máe como elemento de autoridade moral no trânsito entre a dor pessoal e causas coletivas. As mulheres performam o que significa a condição materna na necessidade de "luta". Podemos entender, ainda, que a construção de um lugar de fala como "mães" está em estreita conexão com as construções - sempre em processo - de gênero (VIANNA; FARIAS, 2011).

O sofrimento performado na web, as fotos perturbadoras e os relatos que buscam angariar compaixão podem ser também compreendidos como formas de luta. Moreira, Mendes e Nascimento (2018), trazendo experiências de mães de crianças nascidas com a síndrome congênita pelo zika vírus, destacam o protagonismo feminino na construção de denúncias públicas contra um Estado ausente nas ações de prevenção à epidemia. Há também um paralelo entre o uso das fotos de crianças com deficiências ou dependências tecnológicas visíveis e aquelas dos corpos dos jovens vitimados pela violência policial no artigo de Vianna e Farias. Aqui nos lembramos do movimento, citado anteriormente, das mães que divulgaram fotos dos filhos deficientes no chão de banheiros públicos. As imagens chocam, provocam o olhar de quem está "de fora". De forma similar, a produção de narrativas favorece a tessitura de novos significados, e sua visibilidade na web potencializa o alcance das construçóes compartilhadas. O modelo cultural que apresenta a equação doença-malinfelicidade, embora ainda hegemônico, permite alternativas simbólicas. As mães que se veem excluídas das construçôes de felicidade associadas contemporaneamente à criação de filhos típicos podem, por exemplo, colocar tais padrôes de normalidade e felicidade entre parênteses e trilhar novos caminhos para além daqueles de mãemártir-sofredora ou mãe-especial-poderosa.

A mãe de uma criança escreve sobre a percepção social da gastrostomia de sua filha.

A mensagem que recebi, muito clara, era de que ter uma criança que usa uma sonda para alimentação não é aceitável na sociedade normal. A gastrostomia dava corpo às diferenças da minha filha. (AGRAWAL, 2013, s.p.). 
Falando sobre a criação de uma identidade positiva para as crianças que necessitam desta modificação corporal, a autora diz:

Abrace o tubo. Ele é parte de seu filho, celebre-o! Você pode dar um nome, comprar ade-
sivos para enfeitá-lo ou usar tatuagens temporárias ao redor dele. (...) Deixe que seu filho
o exiba quando está nadando ou se alimentando, se for o que ele quiser fazer. Tire fotos
sem cobrir a gastro. (AGRAWAL, 2013, s.p.).

Citando Marc Augé, Herzlich (2004) chama-nos a atenção para o grande paradoxo da experiência da doença: ser ela a mais individual e a mais social das coisas. A autora mostra como os laços entre o domínio privado e o público passaram por transformaçôes frequentes no campo da saúde e da doença. A internet reatualiza a discussão dos domínios público e privado. Mulheres marcadas por experiências de sofrimento e cuidado intensas e profundamente pessoais passam a escrever e disponibilizar seus escritos em plataformas digitais.

Honneth (2003) postula ser a luta por reconhecimento a força moral que promove desenvolvimentos e progressos na realidade da vida social do ser humano. Todos temos expectativas profundamente arraigadas de reconhecimento, ligadas à identidade pessoal e a padrôes sob os quais um sujeito pode se saber respeitado em seu entorno sociocultural. Se essas expectativas normativas são desapontadas pela sociedade, isso desencadeia sentimentos de lesão. Tais sentimentos podem tornar-se base motivacional de resistência coletiva quando o sujeito é capaz de articulá-los num quadro de interpretação intersubjetiva que os comprova como típicos de um grupo inteiro. Nesse sentido, o surgimento de movimentos sociais depende da existência de uma semântica coletiva que permite interpretar as experiências de desapontamento pessoal como algo que afeta não só o eu individual, mas também um círculo de muitos outros sujeitos. (HONNETH, 2003, p. 258.)

A possibilidade de contato entre indivíduos que compartilham experiências semelhantes é extraordinariamente ampliada com o advento das tecnologias de comunicação. Muitos estudos têm abordado comunidades on-line que agregam pessoas com um mesmo diagnóstico ou condição (GILLETT, 2003; PEREIRA NETO et al., 2015; SOPHIA, 2013), demonstrando como a interação propicia construçóes coletivas sobre os significados de se viver com uma determinada doença ou condição: "A rede mundial de computadores se tornou um grande laboratório, um terreno propício para experimentar e desenvolver novas subjetividades e outras formas 
de se relacionar com os demais" (SIBILIA, 2016). Construçôes de identidade baseadas em características biológicas ou sua negação, por exemplo, são assim favorecidas.

Sem a pretensão de desenvolver uma análise linguística das narrativas que compóem a revista Complex Child, importa-nos incorporar esta dimensão da prática discursiva como constitutiva da vida social. Torna-se imprescindível compreender, no discurso das mães, que a própria identidade é um processo intersubjetivo, dialógico e relacional, colocado no território da multiplicidade, do dinamismo, da fragmentação e da contradição (MOITA-LOPES, 2002). Se consideramos, como Fabricio e Moita-Lopes (2002), que os efeitos de sentido estão sempre submetidos ao olhar do outro, sendo afetados pelo contexto emergente, podemos ter a dimensão do alcance que um projeto de abertura de si a partir dos meios digitais pode ter.

O nome da revista Complex Child oferece uma pista identitária: uma definição das mulheres a partir de seus filhos complexos ainda que, propositadamente, a editora não defina o que seja uma criança complexa.

A dimensão de projeto aí se insinua. Quando nos distanciamos da idealização de uma felicidade-mercadoria, confundida com fruição de prazeres e com facilidade, e passamos a entendê-la como busca de sentido, a questão deixa de ser se apreciamos nossas vidas, ou mesmo se temos um senso de bem-estar subjetivo. Para Solomon (2015), a felicidade é, sobretudo, uma questão de como avaliamos o curso de nossas vidas, dadas nossas aspiraçóes e nossos valores, o que realmente queremos fazer ou realizar em futuros que se constroem no cotidiano. No processo de escrita e compartilhamento de suas experiências na revista, as mães de crianças complexas parecem acessar essa felicidade-sentido sempre de forma dinâmica e instável.

\section{Considerações finais}

O acervo da revista Complex Child configura um campo no qual se evidencia uma relação nativa com o sofrimento. Conforme vimos, a performance de sofrimento pode ser instrumento de conexão, veicular significados ligados ao feminino e ao cuidado, bem como buscar canalizar emoçôes como a compaixão e até chegar a compor uma gramática de luta, afirmação de diferenças e veiculação de denúncias.

A internet é um importante recurso de aproximação e vinculação ao ensejar a circulação de narrativas contra-hegemônicas. Mostrar o rosto e o nome, próprios e do filho, pode fazer parte de um movimento que afirme uma individualidade 
sofredora, mas pode também culminar na produção de novos sentidos, ampliando o campo de possibilidades, inclusive simbólicas, para mães e crianças com condiçôes crônicas complexas de saúde. Para isso, torna-se necessário, em algum momento, que a dor vinculada numa narrativa individual, privada, íntima, permita uma conexão com outras dores, outras histórias, outras lutas.

A revista se configura como um espaço de construção simbólica de pertencimento, possibilitando que o sentido de projetos de felicidade seja tecido de forma solidária e inclusiva. A realidade internacional é de grande interesse na medida em que antecipa cenários e questôes com os quais, ainda que de forma incipiente, já começamos a nos deparar. ${ }^{3}$

\section{Referências}

AGRAWAL, S. At least it isn't cancer! Complex child, Mar. 2016. Disponível em: <http:// complexchild.org/articles/2016-articles/march/at-least-it-isnt-cancer/>. Acesso em: 7 maio 2018. . Positive tube identity. Complex child, Feb. 2013. Disponível em: <http://complexchild. org/articles/2013-articles/february/positive-tube-identity/>. Acesso em: 7 maio 2018.

ALVES, S.P.; BUENO, D. O perfil dos cuidadores de pacientes pediátricos com fibrose cística. Ciência \& Saúde Coletiva. Rio de Janeiro, v. 23, n. 5, p. 1451-1457, 2018.

BIRMAN, J. Muitas felicidades?! O imperativo de ser feliz na contemporaneidade. In: FREIRE FILHO, J. (Org.). Ser feliz hoje: reflexôes sobre o imperativo da felicidade. Rio de Janeiro: Editora FGV, 2010. p. 27-47.

CLARK, C. Misery and company: sympathy in everyday life. University of Chicago Press, 2007.

DAS, V. Trauma y testimonio. In: ORTEGA, F. (Org.). Veena Das: Sujetos del dolor, agentes de dignidad. Bogotá: Instituto Pensar, 2008. p. 145-169.

FABRICIO, B. F.; MOITA-LOPES, L. P. Discursos e vertigens: identidades em xeque em narrativas contemporâneas. Veredas: Rev. Est. Ling. Juiz de Fora, v. 6, n. 2, p. 11-29, 2002.

FAVRET-SAADA, J. Ser afetado. Cadernos de campo, n. 13, np. 155-161, 2005.

FRAGOSO, S.; RECUERO, R.; AMARAL, A. Métodos de pesquisa para internet. Porto Alegre: Sulina, 2011.

FREIRE FILHO, J. O anseio e a obrigação de ser feliz hoje. In: FREIRE FILHO, J. (Org.). Ser feliz hoje: reflexóes sobre o imperativo da felicidade. Rio de Janeiro: Editora FGV; 2010. p. 13-25. GEORGE, R. When this is the best option you have. Ordinary hopes, 2016a. Disponível em: $<$ https://ordinaryhopes.com/2016/06/27/when-this-is-the-best-option-you-have/>. Acesso em: 7 maio 2018. 
. Parent or carer? Ordinary hopes, 2016b. Disponível em: <https://ordinaryhopes. com/2016/11/02/parent-or-carer/>. Acesso em: 7 maio 2018.

GILLETT, J. Media activism and Internet use by people with HIV/AIDS. Sociology of Health and Illness, v. 25, n. 6, p. 608-624, 2003.

GOFFMAN, E. A representação do eu na vida cotidiana. Petrópolis: Editora Vozes, 2002.

HERZLICH, C. Saúde e doença no início do século XXI: entre a experiência privada e a esfera pública. Physis: Rev. Saúde Coletiva. Rio de Janeiro, v. 14, n2, p. 383-394, 2004.

HONNETH, A. Luta por reconhecimento: a gramática moral dos conflitos sociais. Sáo Paulo: Editora 34, 2003.

LABURTHE-TOLRA, P.; WARNIER, J. P. Etnologia antropologia. Petrópolis: Vozes, 1997.

LASCH, C. A cultura do narcisismo. Rio de Janeiro: Imago; 1983.

LEITE, M. F. et al. Condição crônica na infância durante a hospitalização: sofrimento do cuidador familiar. Cienc Cuid Saude, v. 11, n. 1, p. 51-57, 2012.

LORDON, F. A sociedade dos afetos. Campinas: Papirus, 2015.

MARCON, S. S. et al. Dificuldades enfrentadas pela família no cuidado a uma criança com doença crônica. Cienc Cuid Saude, v. 6, n. 2, p. 411-419, 2007.

MILLER, D.; SLATER, D. Etnografia on e off-line: cibercafés em Trinidad. Horizontes antropológicos, ano 10, n. 21, p. 41-65, jan./jun. 2004.

MOITA-LOPES, L.P. Identidades fragmentadas. Campinas: Mercado de Letras, 2002.

MOREIRA, M. C. N. et al. Quando ser raro se torna um valor: o ativismo político por direitos das pessoas com doenças raras no SUS. Cad Saude Pública. Rio de Janeiro, v. 34, n. 1, e00058017, 2018.

. Recomendaçóes para uma linha de cuidados para crianças e adolescentes com condiçóes crônicas complexas de saúde. Cad Saúde Pública. Rio de Janeiro, v. 33, n. 11, e00189516, 2017.

MOREIRA, M. C. N.; MENDES, C. H. F., NASCIMENTO, M. Zika, protagonismo feminino e cuidado: ensaiando zonas de contato. Interface, v. 22, n. 66, p. 697-708, set. 2018.

NUPPONEN, E. The many jobs of a parent-carer. Complex child, Nov. 2017. Disponível em: <http:// complexchild.org/articles/2017-articles/december/many-jobs-carer/>. Acesso em: 7 maio 2018.

PAEZ, A. S.; MOREIRA, M. C. N. Construçôes de maternidade: experiências de mães de crianças com síndrome do intestino curto. Physis: Rev. Saúde Coletiva. Rio de Janeiro, v. 26, n. 3, p. 1053-1072, 2016.

PEREIRA NETO, A. et al. O paciente informado e os saberes médicos: um estudo de etnografia virtual em comunidades de doentes no Facebook. História, Ciências, Saúde-Manguinhos. Rio de Janeiro, v. 22, supl., p. 1653-1671, dez. 2015. 
RANDELL, I. To the doctor who told me not to get attached to my baby. Complex child, Feb. 2018. Disponível em: <http://complexchild.org/articles/2018-articles/february/doctorattached/>. Acesso em: 7 maio 2018.

REZENDE, C.; COELHO, M. C. Antropologia das emoçôes. Rio de Janeiro: FGV; 2010.

SCHAEFFER, S. It is not too late. Loving Lydia, 2014. Disponível em: <https://lovinglydiablog. com/2014/07/09/not-too-late/>. Acesso em: 07 maio 2018.

. Lydia: life after death. Complex Child, mar, 2017. Disponível em: http://complexchild. org/articles/2017-articles/march/lydia-life-after-death/ Acesso em: 07/05/2018.

SCHECHNER, R. O que é performance? In: Performance studies: an introduction. 2a. ed. New York \& London: Routledge, 2006. p. 28-51.

SIBILIA, P. O show do Eu: a intimidade como espetáculo. Rio de Janeiro: Contraponto, 2016.

SILVA, M. A. S. et al. Cotidiano da família no enfrentamento da condição crônica na infância. Acta Paul Enferm, v. 23, n. 3, p.359-365, 2010.

SMITH, J.; CHEATER, F.; BEKKER, J. Parents' experiences of living with a child with a longterm condition. Health Expectations, v. 18, p.452-474, 2013.

SOLOMON, R. Fiéis às nossas emoçóes. Rio de Janeiro: Civilização Brasileira, 2015.

SOPHIA, B. Quando a magreza passa a ser considerada um ideal masculino: um olhar socioantropológico acerca dos transtornos alimentares em homens. Revista Intratextos, v. 4, n. 1, p. 119-139, 2013.

SWALLOW, V. et al. Fathers and mothers developing skills in managing children's longterm medical conditions: how do their qualitative accounts compare? Child: care, health and development, v. 37, n. 4, p. 512-23, 2011.

VÁSQUEZ, G. Maternidade e Feminismo: notas sobre uma relação plural. Revista Trilhas da História. Três Lagoas, v. 3, n. 6 jan-jun, p. 167-181, 2014.

VIANNA, A., FARIAS, J. A guerra das mães: dor e política em situações de violência institucional. Cadernos Pagu, v. 37, p. 79-226, jul-dez 2011.

\section{Notas}

${ }^{1}$ A revista está disponível no endereço <http://complexchild.org/>, sendo que números anteriores a 2012 estấo acessíveis em <http://www.articles.complexchild.com/>.

${ }^{2}$ Utilizamos a primeira pessoa do singular quando é o caso de destacar a reflexividade da primeira autora.

${ }^{3}$ A. S. Paez realizou a pesquisa, analisou os resultados e redigiu o artigo. M. C. N. Moreira orientou a pesquisa e a análise dos resultados, e participou da redação do artigo. 


\section{Abstract}

On the performance of suffering on the web: narratives of mothers of children with complex chronic health conditions in an online journal This paper aims discuss the performance of suffering from the narratives of mothers of children with complex chronic health conditions published in a web journal, also following the trail of some links that lead to blogs. The visibility of shared content on the internet, whatever the platform, and its growing social function of joint construction, leads us to turn our attention specifically to this contemporary space. From an immersion of ethnographic inspiration in the writings, movements generated by the narratives were identified: capture, affirmation of a place, constitution of a vector of forces and symbolic struggle. In the form of an essay, we sought to articulate the empirical material discursively with theoretical questions. Internet is an important resource of approximation and linkage in allowing the circulation of counter-hegemonic narratives. Showing their faces and names and their children's can be part of a movement that affirms a suffering individuality, but can also culminate in the production of new senses, expanding the field of possibilities, including symbolic ones for mothers and children with complex chronic health conditions.

> Keywords: chronic disease; child; narratives. 